\title{
IDENTIFIKASI POTENSI OBJEK WISATA PULAU PANIKI DI DESA KULU KEC. WORI KAB. MINAHASA UTARA
}

\author{
Seska Meily Hermin Mengko ${ }^{1 *}$, Vesty Like Sambeka ${ }^{2}$ 1,2 Prodi D3 Usaha Perjalanan Wisata, Jur. \\ Pariwisata, Politeknik Negeri Manado. E-mal: seskamengko@gmail.com
}

\begin{abstract}
Absract: Identification of Tourism Atrraction Potential of Paniki Island in Kulu Village, Wori Subdistrict, North Minahasa Regency. This research aims to identify the tourism object potential of Paniki Island, and to analyze the local community involvement in Paniki Island tourism development. The method used in this research is descriptive qualitative method by presenting the description and interpretation of the data and information gathered giving it a more interesting presentation. The results of research show that Paniki Island has a very interesting tourism potential, located in the middle of the beach with white sand which glows when exposed to sunshine. The beauty of Paniki Island can be enjoyed during the low tide from 11 a.m up to 4 p.m. In addition, there is a wide stretch of mangrove forest with various species. around the island. This mangrove forest is meant to prevent the coastal abrasion. The tourism potential of Paniki Island is not yet well managed as seen from the unavailability of supporting facilities and infrastructure such as food kiosks, souvenir kiosks, home stays and other kinds of accommodation. One of the entry accesses to Paniki Island is the jety in Kulu village and there are also some motor boats used as sea transportation to Paniki Island. The community involvement is also relatively low as can be seen from the cleanliness around the beach in maintaining the natural conservation. The garbage taken by the visitors to Paniki Island is thrown around the beach and brought to the sea and therefore during the high tide, the location becomes clean again.Thus, there is a need for socialization and training for community involvement in managing the natural tourism object of Paniki Island and maintaining the environmental conservation by not littering around Paniki Island.
\end{abstract}

Key words: Paniki island, potential, community involvement

\begin{abstract}
Abstrak: Penelitian ini bertujuan untuk mengidentifikasi potensi objek wisata pulau paniki, untuk mengidentifikasi potensi objek wisata pulau paniki, dan untuk mengkaji keterlibatan masyarakat lokal dalam pengembangan objek wisata pulau paniki. Metode yang dipergunakan dalam penelitian ini adalah metode deskriptif kualitatif yaitu memberikan ulasan atau interpretasi terhadap data dan informasi yang diperoleh sehingga menjadi lebih menarik di dalam penyajiannya. Hasil penelitian menunjukkan bahwa Pulau Paniki memiliki potensi wisata yang sangat indah, terletak ditengah pantai dengan pasir putihnya yang berkilau saat terkena sinar matahari. Keindahan Pulau Paniki dapat dinikmati pada saat air laut surut pada jam 11.00 siang sampai 16.00 sore. Selain itu disekitar pulau paniki terdapat hamparan hutan mangrove yang luas dengan beragam species yang ada. Hutan mangrove ini bertujuan menangkal abrasi pantai. Potensi wisata pulau paniki belum dikelola dengan baik terlihat dari belum adanya fasilatas dan infrastruktur pendukung pariwisata seperti kios makanan, kios souvenir dan akomodasi homestay atau penginapan lainnya. Salah satu jalur masuk ke Pulau Paniki adalah melalui dermaga yang ada di desa Kulu dan beberapa perahu motor yang digunakan sebagai alat transportasi laut menuju Pulau Paniki. Keterlibatan masyarakat pun masih relative kurang dilihat dari kebersihan di sekitar Pulau Paniki dalam menjaga kelestarian alam. Sampah yang dibawah oleh wisatawan ke pulau paniki masih dibuang di sekitar pantai dan dibawah ke laut sehingga pada saat air pasang lokasi sekitar pulau paniki menjadi bersih kembali. Perlu diadakan sosialisasi dan pelatihan terhadap keterlibatan masyarakat dalam mengelola wisata alam pulau paniki dan menjaga kelestarian alam sekitar dengan tidak membuang sampak di sekitar pulau paniki.
\end{abstract}

Kata Kunci: Pulau Paniki, Potensi, keterlibatan masyarkat

Likupang merupakan salah satu dari 5 destinasi pariwisata yang masuk kategori super prioritas yang ditetapkan oleh pemerintah dalam Kawasan Ekonomi Khusus (KEK) dengan pertimbangan yang terkait dengan prospek sector pariwisata yang sangat menjanjikan yang dimiliki oleh Likupang. Kebijakan utama yang diambil pemerintah yakni menerbitkan 
Undang-Undang Nomor 39 Tahun 2009, tentang Kawasan Ekonomi Khusus/KEK (UU No. 39/2009). Lahirnya UUNo. 39/2009, didasari adanya kebutuhan mempercepat pembangunan sebuah kawasan dan menjaga keseimbangan kemajuan suatu daerah (sebagai kesatuan ekonomi nasional). Terminologi KEK menurut UU No. 39/2009: Kawasan dengan batas tertentu dalam wilayah hukum Negara Kesatuan Republik Indonesia yang ditetapkan untuk menyelenggarakan fungsi perekonomian dan memperoleh fasilitas tertentu. Pemberian fasilitas tertentu atau perlakuan khusus, dimaksudkan agar dunia usaha memiliki perspektif jangka panjang (Pramoda \& Apriliani, 2016). Untuk menunjang program pemerintah tersebut maka banyak hal yang harus dipenuhi termasuk infrastruktur dan utilitas dasar yang wajib ada pada tahun 2020. Infrastruktur yang dimaksud meliputi pelebaran jalan tol, perluasan terminal Bandara Sam Ratulangi, penambahan hotel, serta peningkatan jalan nasional non-tol di Sulawesi Utara. Sementara utilitas dasar yang wajib ada, terkait dengan penyediaan listrik, penyediaan air bersih, dan telekomunikasi. Menteri Pariwisata meminta untuk disediakannya infrastruktur pendukung pariwisata di antaranya penambahan delapan selfie spot baru pada 2019, dilaksanakannya event mingguan dari Agustus hingga Desember 2019, penyediaan sumber daya air, pembangunan TPA sampah regional Mamitamarang (Manado, Kabupaten Minahasa, Kabupaten Minahasa Utara, dan Kota Bitung), pembangunan perumahan swadaya masyarakat, serta peningkatan kualitas aksesibilitas darat (Dimiyati, iNews.id, 2019). Penetapan KEK oleh pemerintah di Likupang yang merupakan bagian dari wilayah Minahasa Utara berdampak pada pembangunan objek-objek wisata lainya yang berada disekitar pantai likupang termasuk didalamnya Desa Kulu yang berdekatan dengan wilayah Likupang Barat.

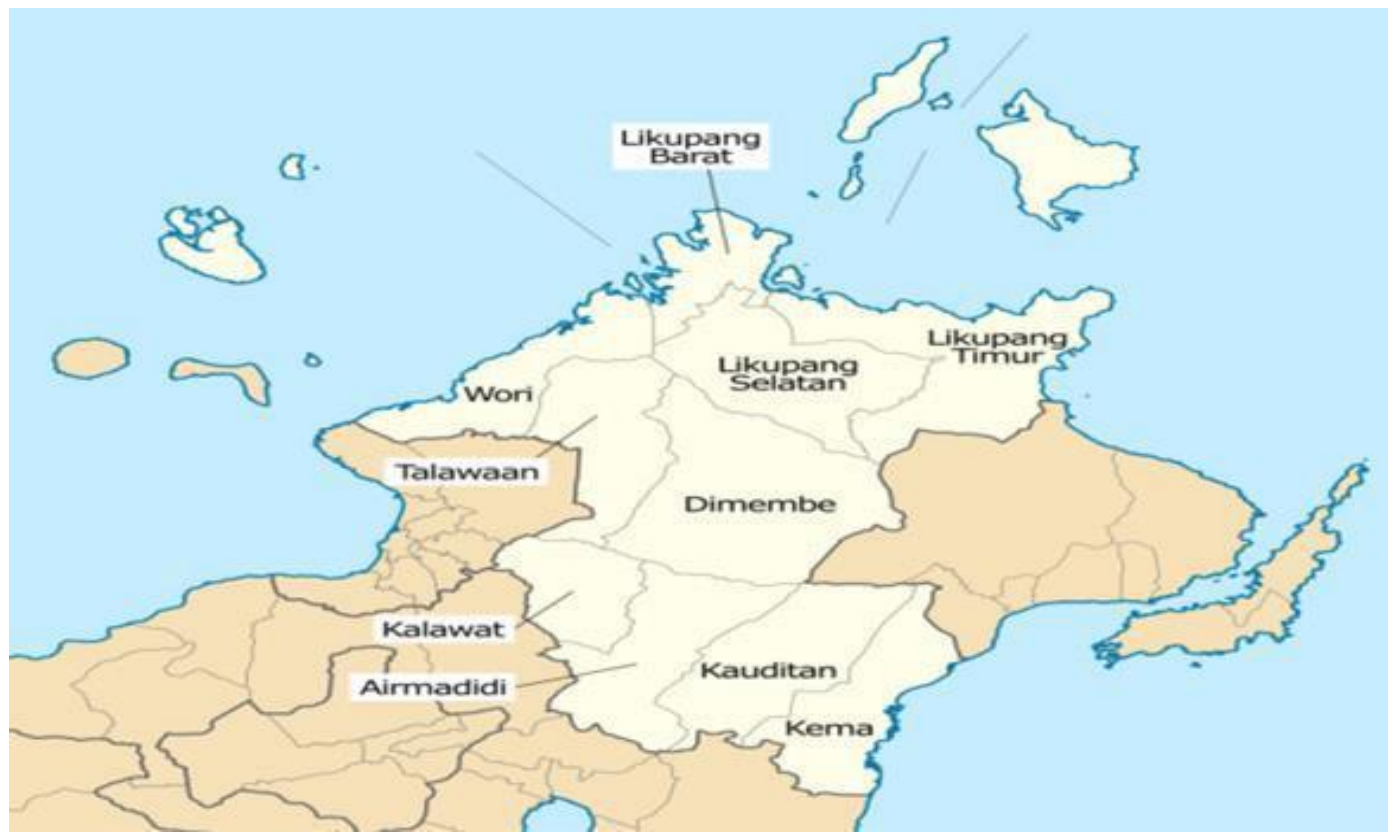

Gambar 1: Peta Desa Kulu (https://www.google.com/search_peta_desa_kulu)

Desa Kulu berada di Kecamatan Wori merupakan desa terakhir dalam daftar desa di kecamatan tersebut karena terletak paling ujung di wilayah Wori. Desa Kulu memiliki objek wisata yaitu Pulau Paniki. Pulau Paniki merupakan pulau kecil yang terletak ditengah pantai yang hanya muncul ketika air laut sedang surut. Pulau ini memiliki potensi wisata yang menakjubkan karena keindahan pulau ini mirip seperti pada film Pirates of the Caribbean.

Pulau Paniki mulai dikenal oleh masyarakat luas setelah ramai dikunjungi sejak tahun 2016 lalu. Kunjungan wisatawan lokal maupun domestik dan internasional ramai pada setiap hari sabtu, minggu dan hari-hari libur nasional. Alat transportasi yang digunakan adalah perahu bermotor dengan jarak tempuh kurang lebih 15 menit dari dermaga yang berada di Desa Kulu. 
Untuk mendapatkan hasil yang terbaik saat berkunjung di pulau paniki adalah pada saat air laut surut yaitu di jam 11.00 siang sampai 16.00 sore. Waktu yang singkat untuk menikmati keindahan pulau paniki namun berkualitas karena disaat-saat seperti itu keindahan pulau paniki akan terlihat dengan jelas. Selain itu pemandangan hutan mangrove yang yang indah mendukung potensi objek wisata pulau paniki. Keindahan pulau paniki belum terexpose secara luas dikarenakan informasi mengenai keberadaan objek wisata pulau paniki ini yang relative minim. Bentuk promosi wisata pulau paniki didapat dari postingan masyarakat melalui akun media social mereka. Bentuk promosi ini sangat efektif karena promosi melalui media social dapat dilihat sebagai medium (fasilitator) online yang menguatkan hubungan antar pengguna sekaligus sebagai sebuah ikatan social (Atiko et al, 2016). Pulau Paniki memiliki potensi untuk dikembangkan menjadi suatu destinasi wisata. Potensi objek wisata Pulau Paniki, dapat dijadikan tempat perputaran ekonomi masyarakat jika di kelola dengan baik. Karena dengan memberikan manfaat dalam bentuk penguatan ekonomi lokal, yang antara lain berupa devisa, pendapatan tambahan kepada masyarakat, serta peluang pekerjaan yang dapat ditangkap oleh masyarakat. Sektor usaha dalam pariwisata seperti usaha akomodasi, transportasi, dan lainnya dapat memberikan kontribusi dalam mendorong perekonomian lokal, regional, maupun nasional (Rahayu et al,2016). Potensi Wisata adalah segala macam bentuk sumber daya yang terdapat disuatu daerah tertentu yang bisa diramu dan dikembangkan menjadi suatu aneka atraksi wisata (Djamaluddin, 2016). Tujuan penelitian ini adalah untuk mengidentifikasi potensi objek wisata pulau paniki, untuk mengidentifikasi potensi objek wisata pulau paniki, dan untuk mengkaji keterlibatan masyarakat lokal dalam pengembangan objek wisata pulau paniki.

\section{METODE}

Penelitian ini dilakukan di Pulau Paniki Desa Kulu Kecamatan Wori Kabupaten Minahasa Utara Propinsi Sulawesi Utara. Metode penelitian yang digunakan adalah metode penelitian kualitatif dengan tehknik deskriptif menggunakan metode observasi terhadap potensi wisata Pulau Paniki termasuk fasilitas pendukung untuk dapat jadikan sebagai destinasi wisata pulau. Observasi dilakukan selama 3 bulan yaitu bulan Mei sampai dengan bulan Tahun 2019. Selain itu metode pengumpulan data juga dilakukan dengan teknik wawancara kepada beberapa informan kunci yaitu penjaga pelabunhan, wisatawan yg berkunjung, pemerintah dan masyarakat setempat, serta pemilik perahu yang membawa wisatawan ke Pulau Paniki yang keseluruhannya berjumlah 20 orang. Seluruh data dikumpul, diolah dan dianalisis dengan pendekatan deskripsif yaitu dengan memberikan ulasan atau interpretasi terhadap data dan informasi yang diperoleh langsung di lapangan.

\section{HASIL DAN PEMBAHASAN}

Desa Kulu terletak diperbatasan antara kecamatan Wori dan kecamatan Likupang Barat Kabupaten Minahasa Utara. Luas wilayah Desa Kulu sekitar 447 Ha yang dibagi menjadi 8 Jaga (dusun). Penduduk berjumlah 1106 jiwa (382 KK) dengan komposisi lakilaki 597 jiwa dan perempuan 589 jiwa. Kebanyakan penduduk di desa ini memiliki mata pencaharian sebagai petani/nelayan, yakni sebanyak 139 orang, pedagang/karyawan swasta sebanyak 81 orang dan PNS sebanyak 9 orang. Jumlah penduduk yang belum memiliki pekerjaan sebanyak 26 orang. Dalam hal tingkat pendidikan, penduduk yang tercatat sebagai mahasiswa sebanyak 40 orang. Mereka yang berpendidikan SLTP dan SLTA sebanyak 515 orang. Desa ini didukung dengan sarana pendidikan, berupa 2 gedung SD dan 1 gedung SLTP. Sarana peribadatan berjumlah 7 gedung gereja. 


\section{Potensi Unggulan Desa Kulu}

Pulau Paniki-Ega Salah satu potensi yang ada di Desa Kulu, yaitu Pulau Paniki (karena sebelumnya banyak terdapat paniki (kelelawar), juga dikenal dengan nama pula Ega - nama seorang nelayan Cina yang beternak kerapu tahun 1992, terletak di bagian barat desa Kulu. Pulau ini menyimpan sejuta pesona dan keindahan alam yang menakjubkan. Saat pertama memasuki pulau ini kita akan melihat hamparan pasir putih yang mengelilingi pulau paniki. Di pulau ini, kita dapat merasakan dan melihat keindahan mangrove yang ada di tengah tengah pulau yang dibungkus apik dengan pasir putih nan indah. Di bagian utara pulau paniki, apabila air surut, akan tampak keindahan pasir putih yang bersih dan indah. Kawasan pasir putih tersebut selama ini telah dimanfaatkan sebagai lokasi wisata, snorkeling dan diving. Lebih ke utara, terdapat pulau Burung yang juga memiliki keindahan yang sama dengan panorama mangrove serta kehidupan satwa liar pada pantai pasir putihnya. Desa Kulu memiliki satu dermaga yang merupakan jalur transportasi keluar masuk ke pulau paniki. Untuk menuju ke pulau Paniki kita dapat menggunakan perahu milik masyarakat desa Kulu dari dermaga desa. Jarak dari dermaga ke pulau ini hanya sekitar 15 menit (Sangian, 2012).

\section{Destinasi Wisata Pulau Paniki}

Pulau Paniki adalah pulau kecil yang terletak di desa Kulu kecamatan Wori. Pulau Paniki memiliki keindahan alam dan pantai yang begitu menakjubkan apalagi saat air surut akan terlihat dengan jelas hamparan pasir putih yang nan cantik dan berkilau. Untuk bisa sampai ke pulau paniki harus melalui dermaga yang berada di desa kulu. Desa ini hanya memiliki satu dermaga dan jarak dari jalan raya ke dermaga sekitar -/+ 500 meter. Setiba di dermaga langsung bisa di temui hamparan hutan mangrove yang mengapit jalan masuk menuju pulau paniki. Dari hasil observasi yang dilakukan, objek wisata pulau paniki inipun belum terkelola dengan baik dilihat dari tidak adanya biaya restribusi masuk menuju pulau paniki oleh pemerintah desa. Selain itu disekitar dermaga hanya terdapat empat kamar toilet umum yang tidak dirawat dengan baik sehingga sudah tidak dapat digunakan lagi dan sebuah rumah warga yang dijadikan pengunjung sebagai tempat untuk mendapatkan informasi mengenai wisata di pulau Paniki.

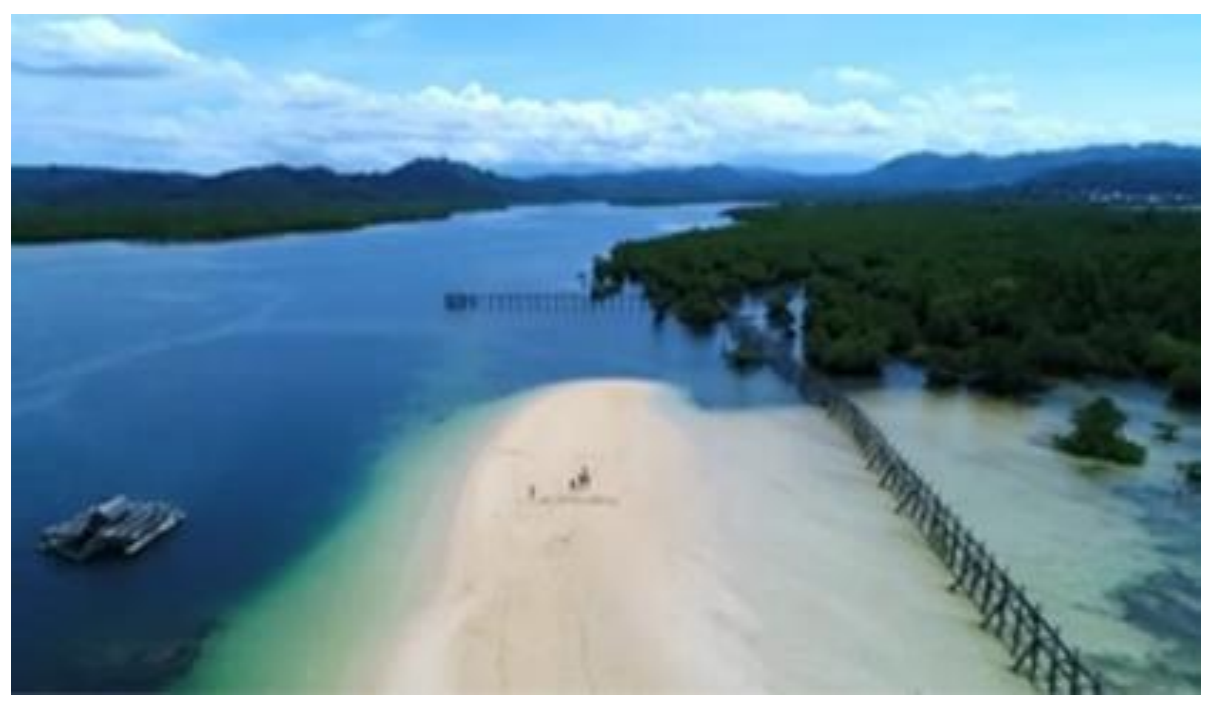

Gambar 3: Keindahan Pulau Paniki: Go Travelly

(https://www.google.com/search?safe_strict\&sxsrf_Alek/)

Di pulau paniki terdapat beberapa jalur trekking yang digunakan sebagai jalur untuk menikmati keindahan hutan mangrove, namun pembangunannya tidak selesai sehingga bagi para pengunjung digunakan sebagai salah satu spot untuk mendokumentasikan keindahan pulau 
paniki seperti gambar di bawah ini. Selain itu terdapat dua gazebo yang digunakan oleh warga sebagai tempat beristirahat. Gazebo ini dibangun oleh PNPM Mandiri melalui program pemberdayaan masyarakat mandiri pedesaan.

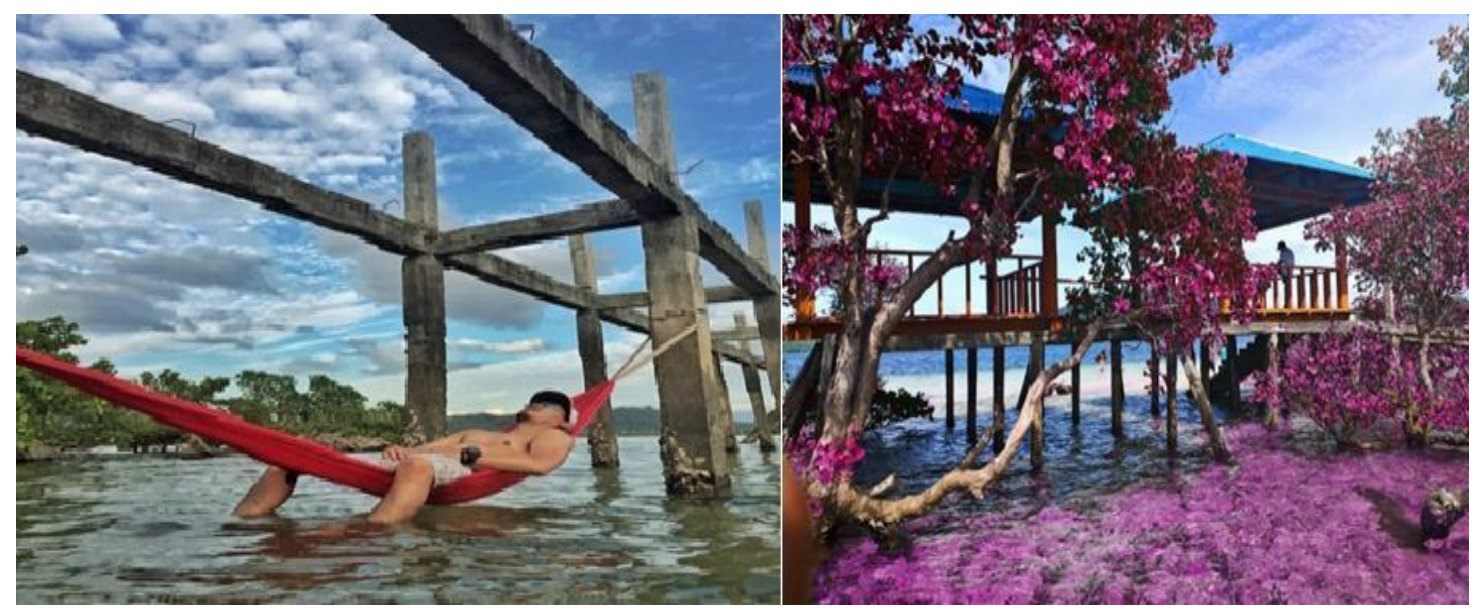

Gambar 5: Jalur trekking yang tidak selesai dan fasilitas Gazebo (https://www.google.com/search?Pulau_paniki_desa_kulu_GoTravely)

Sebagai desa di wilayah pesisir, garis pantai desa kulu merupakan kawasan yang dipadati dengan ekosistem mangrove yang berfungsi sebagai bantaran pelindung garis pantai. Areal hutan mangrove di desa kulu banyak ditumbuhi mangrove dari jenis-jenis Avicennia spp. Rhizhopora spp, Bruguira spp, Sonneratia spp, Ceriops spp dan sebagainya (Marpaung, 2002).

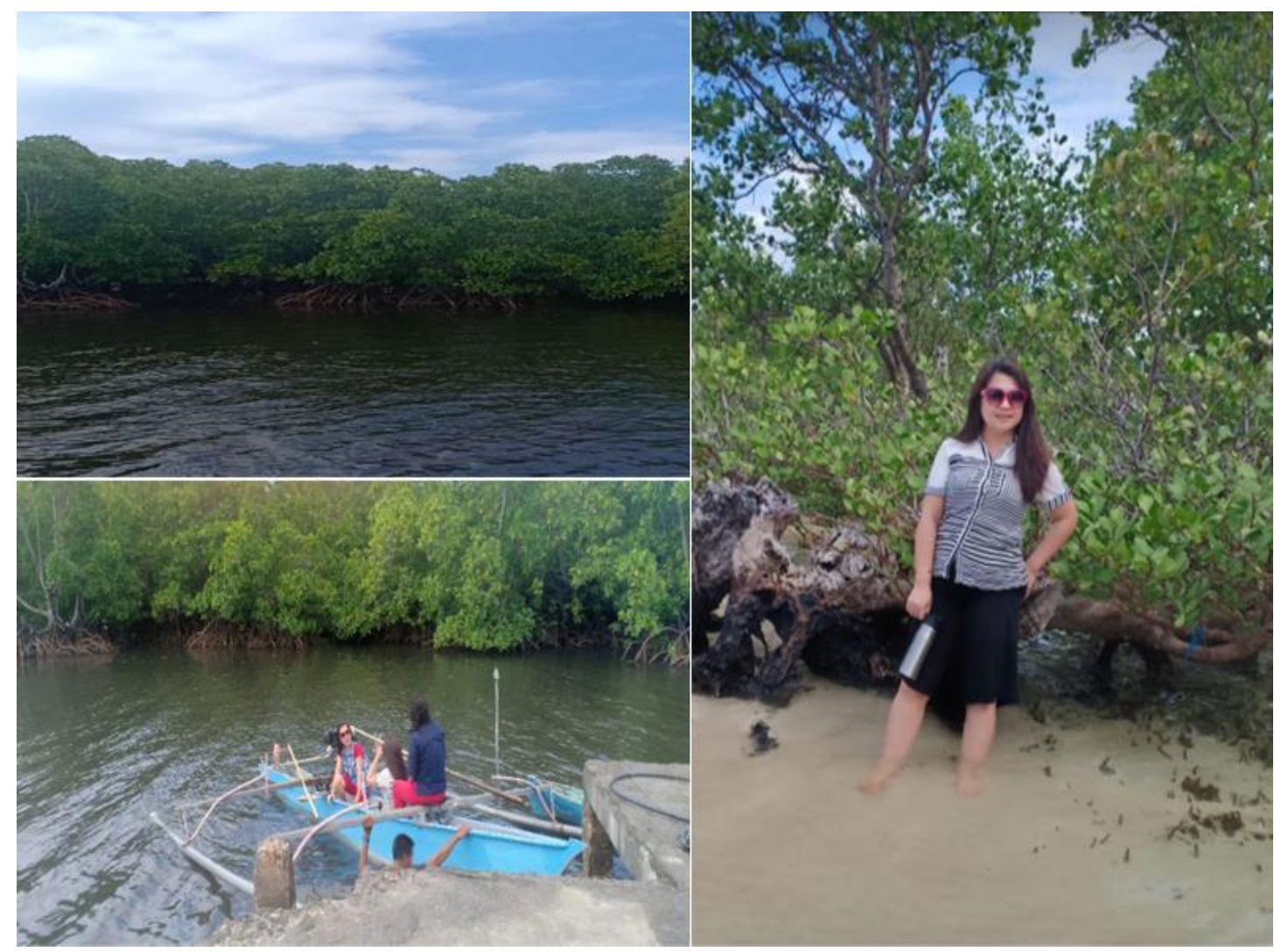

Gambar 6: Kawasan Hutan Mangrove Pulau Paniki (Tim Peneliti, 2019) 


\section{Fasilitas dan Infrastruktur Pariwisata di Desa Kulu}

Desa Kulu memiliki satu dermaga sebagai sarana transportasi laut menuju pulau paniki dengan tiga buah perahu yang merupakan milik warga untuk digunakan sebagai alat transportasi apabila pengunjung hendak ke pulau paniki. Ada tiga ukuran perahu motor yang digunakan yaitu perahu besar untuk memuat 18-24 orang, perahu sedang dengan muatan $15-$ 20 orang, dan perahu kecil untuk $6-12$ orang. Setiap penumpang dikenakan biaya sebesar Rp 25.000 untuk perjalan pulang pergi. Perahu-perahu ini merupakan milik warga sebagai alat untuk mencari nafkah memenuhi kebutuhan hidup keluarga. Setiap hari libur, pulau paniki ramai dikunjungi baik oleh masyarakat lokal maupun wisatawan domestik dan internasional. Operasiaonal transportasi laut ini berlaku dari jam 11.00 siang sampai 16.00 sore sesuai dengan waktu surutnya air laut. Dalam satu hari, satu perahu bisa sampai $3 \mathrm{x}$ memuat penumpang menuju pulau paniki. Lamanya waktu penggunaan perahu tergantung dari permintaan pengunjung apakah carter atau tidak. Carter dalam arti sesampainya di pulau paniki, si pembawa perahu akan menunggu pengunjung sampai mereka kembali ke dermaga.

Fasilitas penunjang lainnya seperti café, restoran, pusat informasi, kios sovernir maupun akomodasi homestay atau penginapan lainnya, sangat disayangkan mengingat mulai ramainya wisatawan datang berkunjung dan jarak yang cukup jauh menuju ke desa kulu, membuat hasrat pengunjung untuk berkongkoh-kongkoh di seputar dermaga sambil menikmati pemandangan hutan mangrove yang indah. Ditribusi masuk ke pulau paniki dikelola secara perorangan dari pemilik perahu belum dikelola oleh pemerintah desa. Terdapat satu rumah di seputaran dermaga yang merupakan milik warga dan rumah itu menjadi tempat persinggahan bagi pengunjung untuk mendapatkan informasi tentang pulau paniki dan bagaimana untuk masuk ke dalamnya.

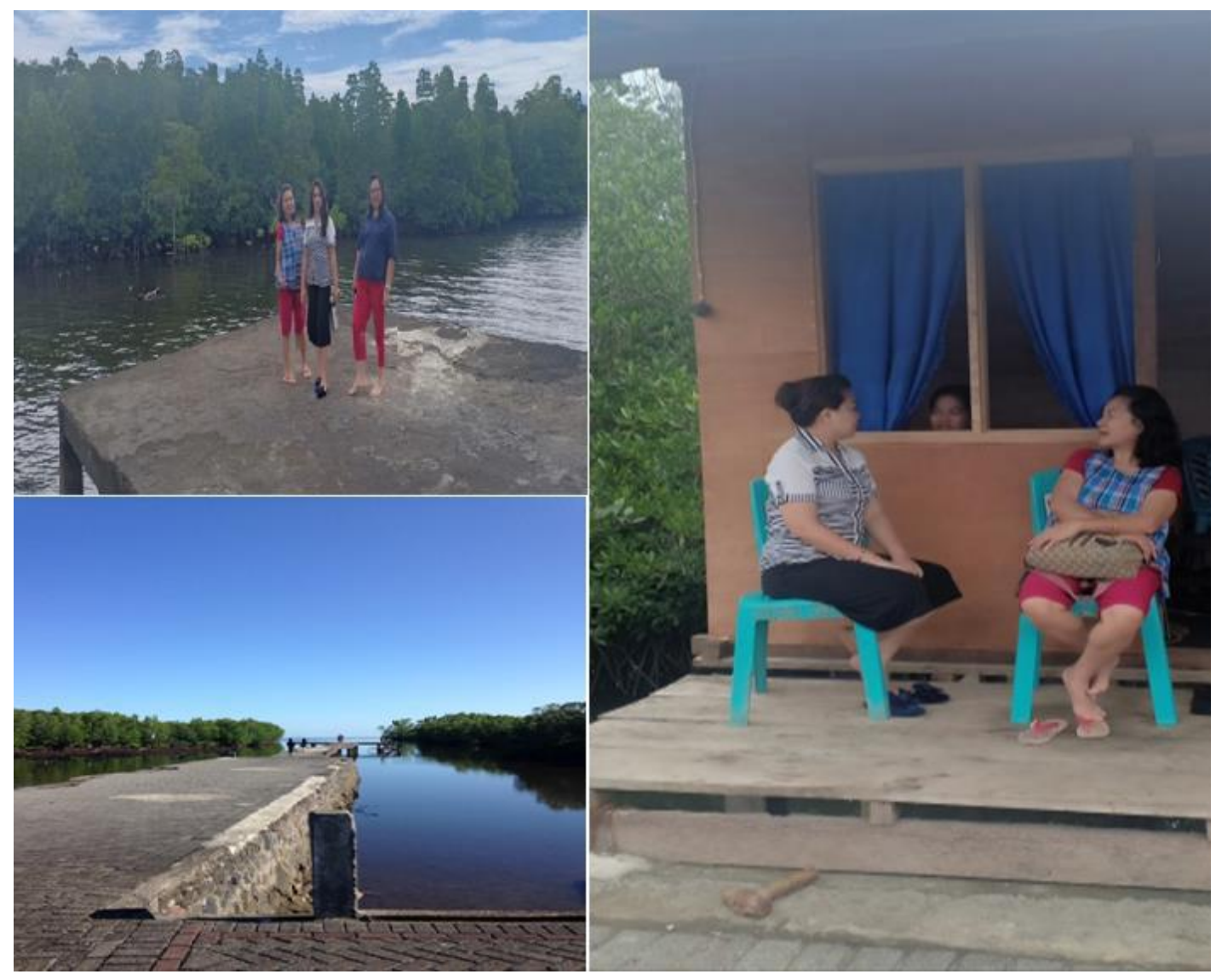

Gambar 7: Hutan Mangrove Mengapit Dermaga Desa Kulu dan Rumah Penduduk Yang dijadikan sebagai Pusat Informasi Wisata Pulau Paniki (Tim Peneliti, 2019) 
Terdapat empat kamar toilet umum yang merupakan fasilitas umum disekitar dermaga, namun fasilitas tersebut tidak berfungsi lagi oleh karena tidak adanya biaya pemeliharaan untuk fasilitas tersebut.

\section{Keterlibatan Pemerintah dan Masyarakat dalam Pengembangan Wisata Desa Kulu}

Keterlibatan masyarakat terhadap potensi wisata di desa kulu relative rendah, oleh karena minimnya pengetahuan mengenai bagaimana memberdayakan potensi wisata mangrove dan pulau paniki sebagai tempat yang dapat menambah income keluarga. Perlu diadakan sosialisasi dan pelatihan terhadap masyarakat untuk bersama mengembangkan desa kulu sebagai desa wisata masgrove dan pulau paniki sebagai wisata alam. Keterlibatan pemerintah untuk mengahadirkan investor dalam mengembangkan potensi wisata di desa kulu mulai dilakukan dengan membangun kerjasama dengan para investor untuk membuka resort disekitar pulau paniki. Salah satu investor dari MM Group ingin melirik pantai paniki di Desa Kulu untuk mengembangkanya objek wisata yang dapat menjadi salah satu destinasi wisata di Kabupaten Minahasa Utara yang dapat membuka lapangan pekerjaan untuk masyarakat dan menamba pendapatan daerah, desa dan ekonomi masyarakat sekitar tempa wisata. Selain itu Bank BRI juga turut membantu lewat program pemerintah melalui Kredit Usaha Rakyat (KUR), kepada masyarakat agar dapat membuat usaha untuk berjualan di sekitar tempat wisata. Apabila ada upaya pengembangan Pulau Paniki dari pemerintah untuk dijadikan sebagai salah satu destinasi wisata, maka harus melihat dari beberapa faktor yang saling memperngaruhi dan mempunyai hubungan keterkaitan yang dapat dijadikan sebagai dasar pengembangan yang sesuai seperti attraction (atraksi), accessibility (keterjangkauan), amenities (fasilitas/ kenyamanan), dan ancillary services (jasa kelembagaan dan promosi) (Mengko et al, 2018) tanpa mengabaikan potensi budaya dan kearifan lokal dalam bidang pariwisata yang dapat menjadi kecenderungan potensi wisata di masa depan (Rahma, 2020).

\section{SIMPULAN}

Pulau Paniki memiliki banyak potensi wisata Pulau Paniki yang dapat dijadikan dasar pengembangan pariwisata di Desa Kulu. Hal ini diperlukan keterlibatan masyarakat dalam merumuskan model pengembangan objek wisata pulau paniki dengan tidak merubah tatanan kehidupan masyarakat berdasarkan kearifan local yang berlaku. Keterlibatan pemeritah dalam upaya pengembangan destinasi wisata Pulau Paniki sangat diperlukan guna menunjang program pemerintah Nawa Cita yang ke 7 yaitu mewujudkan kemandirian ekonomi dengan menggerakkan sector-sektor strategis ekonomi domestik dibidang pariwisata. dalam meningkatkan perekonomian masyarakat desa pinggiran melalui pariwisata. Sebagai salah satu desa di Kabupaten Minahasa Utara yang memiliki potensi wisata yang dapat menarik pengunjung dan meningkatkan ekonomi masayarakat, maka perlu dilakukan pelatihan dan sosialisi mengenai pengelolaan objek wisata di desa kulu. Bekerja sama dengan pemerintah dan akademisi membangun desa kulu sebagai desa wisata mangrove dan pulau paniki sebagai destinasi wisata alam.

\section{DAFTAR RUJUKAN}

Atiko, G., Sudrajat, R. H., \& Nasionalita, K. (2016). Analisis Strategi Promosi Pariwisata Melalui Media Sosial Oleh Kementrian Pariwisata Ri (studi Deskriptif Pada Akun Instagram@ indtravel).eProceedings of Management, 3(2).

Dimiyati Vien, iNews.id, (2019). Ditargetkan Jadi Wisata Kelas Dunia, KEK Likupang Akan Dibuatkan 8 Spot Selfie

Djamaluddin Rignolda, (2016). Profil, Sejarah dan Potensi Unggulan Desa Minahasa Utara, Pusat Pengelolaan dan Pengembangan Kuliah Kerja Nyata Terpadu, Lembaga Penelitian dan Pengabdian Kepada Masyarakat Unsrat, Manado. ISBN 978-602-74897-0-7 
https://www.inews.id/travel/destinasi/ditargetkan-jadi-wisata-kelas-dunia-kek-likupang-akandibuatkan-8-spot-selfie Inews 10 Agustus 2019

Marpaung, H. (2002). Pengetahuan Kepariwisataan Edisi Revisi. Bandung: Alfa Beta. Mengko, S. M. H., Wenas, P. L., \& Kalele, S. R. (2018). Pal Beach Tourism Development in Marinsow Village, North Minahasa Regency. Journal of Indonesian Tourism and Development Studies, 6(2), 93.

Pramoda, R., \& Apriliani, T. (2016). Kebijakan Penetapan Bitung Sebagai Kawasan Ekonomi Khusus (KEK). Jurnal Borneo Administrator, 12(2), 149-169.

Rahayu, S., Dewi, U., \& Fitriana, K. N. (2016). Pengembangan Community Based Tourism Sebagai Strategi Pemberdayaan Ekonomi Masyarakat Di Kabupaten Kulon Progo, Daerah Istimewa Yogyakarta. Jurnal Penelitian Humaniora UNY, 21(1).

Rahma, A. A., (2020). Potensi Sumber Daya Alam dalam Mengembangkan Sektor Pariwisata di Indonesia. Jurnal Nasional Pariwisata, 12 (1), 1-8.

Sangian, M.M.., (2012). Kajian Potensi Ekowisata Ekosistem Mangrove Dan Prospek Pengembangannya Di Perairan Desa Kulu Kecamatan Wori Kabupaten Minahasa Utara Provinsi Sulawesi utara, Tesis, Universitas Samratulangi. 